\title{
Metodologias ativas: uma inovação que pode virar modismo
}

\author{
Active Methodologies: an innovation that may become fashionable \\ Metodologías activas: una innovación que podría ponerse de moda
}

Recebido: 20/10/2021 | Revisado: 28/10/2021 | Aceito: 02/11/2021 | Publicado: 03/11/2021

\author{
Francisco Eteval da Silva Feitosa \\ ORCID: https://orcid.org/0000-0003-0913-3427 \\ Universidade Federal do Amazonas, Brasil \\ E-mail: sfeitosa@ufam.edu.br \\ Ana Acácia Pereira Valente \\ ORCID: https://orcid.org/0000-0002-6599-6510 \\ Universidade Federal do Amazonas, Brasil \\ E-mail: avalente@ufam.edu.br
}

\begin{abstract}
Resumo
Este artigo apresenta uma discussão teórica que busca contribuir para a seguinte questão: que fazer para que as metodologias ativas não sejam apenas um modismo? A pesquisa tem uma abordagem qualitativa com delineamento de um estudo bibliográfico. O corpus da pesquisa considerou primeiramente o conceito de metodologias ativas segundo diversos autores. Em resposta ao tema central da pesquisa, defendemos a ideia de que o compartilhamento de experiências acerca do uso das metodologias ativas, em todos os níveis de ensino, em todos os tipos de espaços e com os mais variados recursos, incluindo cursos de formação de professores, que fazem uso dessas metodologias e atividades desenvolvidas que sejam fundamentadas teoricamente, são maneiras que podem fazer com que as metodologias produzam efeitos significativos e duradouros na educação. Apenas discussões quanto à epistemologia das metodologias ativas ou críticas não construtivas sobre seu uso pouco contribuirão para a Educação. Consideramos a ideia de que essas metodologias são hoje a melhor opção que temos para a promoção de uma educação de qualidade. Palavras-chave: Metodologias ativas; Inovação; Modismo.
\end{abstract}

\begin{abstract}
This article presents a theoretical discussion that seeks to contribute to the following question: what should be done so that active methodologies are not just a fad? The research has a qualitative approach with a bibliographic study design. The research corpus first considered the concept of active methodologies according to several authors. In response to the central theme of the research, we defend the idea that sharing experiences about the use of active methodologies, at all levels of education, in all kinds of spaces and with the most varied resources, including teacher training courses that make use of these methodologies and developed activities that are theoretically grounded, are ways that can make the methodologies produce significant and lasting effects in education. Only discussions about the epistemology of active methodologies or unconstructive criticism of their use will contribute little to education. We consider the idea that these methodologies are today the best option we have for the promotion of quality education.
\end{abstract}

Keywords: Active methodologies; Innovation; Fad.

\section{Resumen}

Este artículo presenta una discusión teórica que pretende contribuir a la siguiente pregunta: ¿qué hay que hacer para que las metodologías activas no sean sólo una moda? La investigación tiene un enfoque cualitativo con un diseño de estudio bibliográfico. El corpus de investigación consideró en primer lugar el concepto de metodologías activas según varios autores. En respuesta al tema central de la investigación, defendemos la idea de que compartir experiencias sobre el uso de las metodologías activas, en todos los niveles educativos, en todo tipo de espacios y con los más variados recursos, incluyendo cursos de formación del profesorado que hagan uso de estas metodologías y actividades desarrolladas con fundamento teórico, son vías que pueden hacer que las metodologías produzcan efectos significativos y duraderos en la educación. Sólo las discusiones sobre la epistemología de las metodologías activas o la crítica no constructiva de su uso contribuirán poco a la educación. Consideramos que estas metodologías son hoy la mejor opción que tenemos para promover una educación de calidad.

Palabras clave: Metodologias activo; Innovación; Moda.

\section{Introdução}

Atualmente, todos os níveis de ensino têm características predominantes de métodos de ensino utilizados no início do século XIX. Verifica-se, também, que a tecnologia permeia todos os aspectos da vida humana contemporânea. Esses dois fatos 
criam um abismo no tripé fundamental de qualquer situação didática: professor, aluno e saber. A sociedade do século XXI encontra-se imersa, em uma rede de informações, que é acessível a todos, graças aos avanços das Tecnologias Digitais da Informação e Comunicação (TDIC), incorporadas ao nosso dia a dia o que tem provocado mudanças significativas na forma como os indivíduos interagem.

Os estudantes de hoje passam horas diante de um computador ou de um smartphone, inteiramente concentrados. Por outro lado, os mesmos estudantes encontram enormes dificuldades de manterem-se atentos, por apenas $50 \mathrm{~min}$, em uma aula tradicional de Matemática. Portanto é evidente a necessidade de provocarmos uma mudança, no processo de ensinoaprendizagem, buscando alternativas ao modelo de ensino tradicional que é centrado no papel do professor, o qual repassa aos alunos uma gama de conhecimentos previamente estruturados.

De acordo com as avaliações ou parâmetros pré-estabelecidos nacional e até internacionalmente, para a avaliação do ensino, há evidências claras de que o Brasil está muito distante de uma educação de qualidade. O desempenho dos estudantes, em avaliações nacionais, como o Sistema de Avaliação da Educação Básica (SAEB) ou o Exame Nacional do Ensino Médio (ENEM) e em avaliações internacionais como o Programa Internacional de Avaliação de Estudantes (PISA) ou mesmo em olimpíadas de conhecimento como a Olimpíada Brasileira de Matemática das Escolas Públicas (OBMEP), não deixam dúvidas de que o modelo tradicional de ensino, com aulas expositivas e estrita a memorização de conteúdos, já não é suficiente para garantir um aprendizado que corresponda às atuais expectativas dos alunos e, tampouco, do mercado de trabalho.

Diversos são os fatores que contribuem para estarmos na situação atual. Podemos citar, por exemplo, as políticas públicas inadequadas à educação, à desvalorização do trabalho docente e tantos outros. Porém mudar esse quadro é necessário. Urge o desenvolvimento de ações que tenham objetivos bem definidos e alinhados com as atuais necessidades para a aprendizagem significativa do aluno.

Nesse contexto, emergem as chamadas metodologias ativas. Existem muitos trabalhos acerca deste tema, alguns apontam essas metodologias como uma inovação, enquanto outros apenas como um modismo. Neste trabalho, defenderemos a tese de que as metodologias ativas são uma inovação, isto é, são capazes de introduzir novidades em sala de aula e renovar a complexa relação professor-aluno-saber. Mas também somos cientes de que, dependendo da forma como são apresentadas e abordadas, podem tornar-se um modismo, ou seja, durar pouco e desaparecer sem provocar efeitos significativos e duradouros na sala de aula.

\section{Metodologia}

Esta pesquisa tem uma abordagem qualitativa. Segundo Creswell (2010, p. 26):

A pesquisa qualitativa é um meio para explorar e para entender o significado que os indivíduos ou os grupos atribuem a um problema social ou humano. O processo de pesquisa envolve as questões e os procedimentos que emergem, so dados tipicamente coletados no ambiente do participante, a análise dos dados indutivamente construída a partir das particularidades para os temas gerais e as interpretações feitas pelo pesquisador acerca dos significados dos dados.

Quanto aos procedimentos técnicos adotados, esta pesquisa caracteriza-se como bibliográfica, que para Gil (2008, p.50) é "desenvolvida a partir de material já elaborado, constituído principalmente de livros e artigos científicos". Para o levantamento da bibliografia, foram selecionados artigos publicados em periódicos nacionais, entre os anos de 2001 e 2021 . A pesquisa pelos textos se deu a partir da palavra-chave: "metodologias ativas" na base de dados do Google Acadêmico. Ao pesquisar uma expressão entre aspas, o buscador entende que você quer encontrar as palavras-chave exatamente naquela ordem, e não em outra disposição aleatória. A base de dados nos retornou 17200 resultados, excluindo citações.

Usamos a opção "Artigos relacionados" para ter acesso à lista de obras semelhantes em cada resultado de busca. Essa 
função do Google Acadêmico ajuda a encontrar materiais com diferentes pontos de vista sobre o mesmo assunto. Observamos que usando essa função em qualquer um dos 10 primeiros resultados da etapa anterior, a base de dados nos retornava 101 resultados. Restringimos nossa busca a estes 101 trabalhos.

A partir do proposto por Gil (2008), foi realizada uma leitura exploratória dos 101 trabalhos selecionados. Contudo, como próprio autor ressalta, nem tudo é necessariamente lido, pois, nem tudo será importante para alcançar os propósitos da pesquisa. Portanto, foi feita uma leitura exploratória, verificando se existiam ou não informações a respeito do uso e eficácia das metodologias ativas. Buscou-se ainda, trabalhos com posicionamentos contrários ou críticas as essas metodologias. Lemos o título e o resumo dos trabalhos e aqueles que se mostraram pouco pertinente foram deixados de lado. Nessa leitura, foram selecionados 15 artigos determinando o material que foi utilizado na pesquisa.

\section{Conceito de Metodologias Ativas}

O termo "metodologias ativas" é recente, porém, quando olhamos para as características dessas metodologias e algumas das sistematizações e das estratégias que estruturam tais metodologias, percebemos alguns pontos em comum que as caracterizam. Nesta seção, apresentamos como alguns autores que se debruçaram a estudar o processo das metodologias ativas as conceituam.

Para Deponti e Bulegon (2018), metodologias ativas são aquelas que criam oportunidades, para que questões contextualizadas no dia a dia do estudante sejam trabalhadas no espaço educacional e proporcionam experiências inovadoras das práticas pedagógicas e abordam diferentes jeitos de ensinar e de aprender. Marin et al. (2010) enxergam as metodologias ativas como formas de ensino-aprendizagem e de organização curricular, na perspectiva de romper com os métodos tradicionais de ensino-aprendizagem, integrando teoria e prática, além de buscar desenvolver a capacidade de reflexão dos estudantes sobre problemas reais e a formulação de ações originais e criativas capazes de transformar a realidade social.

Moran (2017) declara que as metodologias ativas são estratégias de ensino centradas na participação efetiva dos estudantes, na construção do processo de aprendizagem, de forma flexível, interligada, híbrida, que uma situação de aprendizagem é ativa, a partir do momento em que dá ênfase ao papel protagonista do aluno, ao seu envolvimento direto, participativo e reflexivo, em todas as etapas do processo, experimentando, desenhando, criando, com orientação do professor. Para Moran (2017, p.2):

As metodologias ativas num mundo conectado e digital se expressam, por meio de modelos de ensino híbridos, com muitas possíveis combinações. A junção de metodologias ativas com modelos flexíveis, híbridos traz contribuições importantes para o desenho de soluções atuais para os aprendizes de hoje.

Diesel et al. (2017), no intuito de esclarecer o que se entende por uma abordagem pautada em metodologias ativas de ensino, apresentam o que, segundo eles, são os princípios básicos de tais abordagens: aluno no centro do ensino e da aprendizagem, autonomia, reflexão, problematização da realidade, trabalho em equipe, inovação e o professor como mediador, facilitador. Na sequência, Diesel et al. (2017) articulam cada um desses princípios com correntes teóricas consagradas.

Na perspectiva de Bastos (2006, p.1), metodologias ativas são "processos interativos de conhecimento, análise, estudos, pesquisas e decisões individuais ou coletivas, com a finalidade de encontrar soluções para um problema". De acordo com o autor, esse tipo de metodologia constitui-se em um cenário que desperta a curiosidade do estudante e no qual o professor atua como facilitador ou orientador, fornecendo condições, para que o estudante pesquise, reflita e decida por ele mesmo, apresentando soluções em consonância com o perfil psicossocial da comunidade na qual está inserido.

Berbel (2011) entende as metodologias ativas como maneiras de desenvolver o processo de aprender, utilizando experiências reais ou simuladas, visando às condições de solucionar, com sucesso, desafios advindos das atividades essenciais 
da prática social, em diferentes contextos. Para Mitre et al. (2008), metodologias ativas utilizam a problematização como estratégia de ensino-aprendizagem, com o objetivo de alcançar e motivar o discente, pois, diante do problema, ele se detém, examina, reflete, relaciona a sua história e passa a ressignificar suas descobertas.

Pereira (2012) demonstra por metodologia ativa todo o processo de organização da aprendizagem (estratégias didáticas), cuja centralidade do processo esteja, efetivamente, no estudante, contrariando, assim, a exclusividade da ação intelectual do professor e a representação do livro didático como fontes exclusivas do saber na sala de aula. Segundo o autor:

A metodologia ativa tem suas raízes procedimentais no pensamento pedagógico de autores ligados ao movimento da Escola Ativa e Educação Integrada cujo princípio educativo é o trabalho intelectual, estético e laboral. Nesse caso, uma prática de ensino que guarda em si várias possibilidades de organização de ações didáticas e visa, sobretudo, ao processo de aprender tendo como referência a inserção progressiva do acadêmico no universo profissional de sua formação, resolvendo problemas e aprofundando sua compreensão (Pereira, 2012, p.6).

Valente (2018) assinala que as metodologias ativas são entendidas como práticas pedagógicas alternativas ao ensino tradicional. Em vez de o ensino baseado na transmissão de informação, da instrução bancária, nessas metodologias, o aluno assume uma postura mais participativa, na qual ele resolve problemas, desenvolve projetos e, com isso, cria oportunidades para a construção de conhecimento. Na concepção da autora:

As metodologias ativas constituem alternativas pedagógicas que colocam o foco do processo de ensino e de aprendizagem no aprendiz, envolvendo-o na aprendizagem por descoberta, investigação ou resolução de problemas. Essas metodologias contrastam com a abordagem pedagógica do ensino tradicional centrado no professor, que é quem transmite a informação aos alunos (Valente, 2018, p.27).

Ferreira et al. (2018) afirmam que o conceito de metodologias ativas de aprendizagem corresponde a um ambiente, no qual o aluno é ativo no seu processo de aprendizagem, ouvindo, vendo, perguntando, discutindo e ensinando para desenvolver habilidades e conhecimento e dominar o conteúdo. Além disso, a leitura, a escrita, a análise, a síntese e a avaliação são constantes. Barbosa e Moura (2013) caracterizam as metodologias ativas de aprendizagem como práticas de ensino que favoreçam ao discente as atividades de ouvir, ver, perguntar, discutir, fazer e ensinar. Segundo os autores, para se envolver ativamente no processo de aprendizagem, o discente pode ler, escrever, perguntar, discutir ou estar preparado para resolver problemas e elaborar projetos. Nesse contexto, o uso da tecnologia é parte do processo.

Existem inúmeros outros trabalhos que abordam essa temática, contudo, a partir dos pontos de vista apresentados, já podemos perceber um conjunto de informações básicas que permitem caracterizar uma metodologia de ensino como metodologia ativa.

Assim, identificamos que a metodologia, em um determinado contexto de ensino, é uma metodologia ativa, quando rompe, em parte ou por completo, com os métodos tradicionais de ensino-aprendizagem e integra teoria e prática, por meio da resolução de problemas, envolvendo o contexto em que o aluno está inserido. Tais problemas ou desafios devem despertar a curiosidade do estudante de modo a exigir dele uma postura participativa, promovendo uma motivação intrínseca, desenvolvendo sua autonomia, o espírito crítico-reflexivo e a habilidade de trabalhar em grupo.

Outras duas características comumente apontadas na literatura acerca das metodologias ativas são: o aluno no centro do processo de ensino-aprendizagem e o professor como mediador ou facilitador desse processo. Entendemos que esse tema merece uma discussão mais aprofundada o que foge aos objetivos, porém será matéria de um próximo trabalho. Na próxima seção, argumentaremos a tese de que as metodologias ativas podem, sim, ser consideradas como uma inovação na educação. 


\section{Metodologias Ativas: uma Inovação}

Lembramos que a palavra "inovação" significa novidade, aquilo que é novo, o que apareceu recentemente. Inovar significa realizar algo novo ou que nunca havia sido feito antes. Para Christensen et al. (2013), existem dois tipos de inovações, a sustentada e a disruptiva. Segundo os autores:

A opção sustentada é inventar uma solução híbrida que dê aos educadores "o melhor dos dois mundos" — isto é, as vantagens do ensino online combinadas a todos os benefícios da sala de aula tradicional. A opção disruptiva é empregar o ensino online em novos modelos que se afastem da sala de aula tradicional, e foquem inicialmente nos não consumidores que valorizem a tecnologia pelo que ela é - mais adaptável, acessível e conveniente (Christensen et al.,2013, p.26).

Não vemos argumentos para negar que um professor que implementa uma metodologia, como, por exemplo, o modelo híbrido rotação por estações, não está inovando em sua sala de aula. Numa escola em que prevaleçam as aulas expositivas, um professor que aplica a metodologia aprendizagem baseada em problemas ou aprendizagem baseada em projetos, está com toda a certeza inovando.

As metodologias ativas têm sido questionadas, em seus princípios, cujos estudiosos evidenciam, em seus argumentos, que percebem essas metodologias como diminutas e sem significado real para o ensino, não refletem avanço na prática. Que "propicia o imediatismo, o fortalecimento do pragmatismo profissional e provoca confusões teóricas sobre a relação entre teoria e prática" (da Silva, 2019, p.147). Criticam sobre o que chamam de "filiação pedagógica", alegando ser confusa e argumentam que nessas metodologias, não há nada de inovador, mas somente uma modernização de premissas ou propostas pedagógicas amplamente conhecidas, experimentadas (Pacheco, 2014) e que trata-se de um novo rótulo para práticas antigas, pouco contribui para a Educação (Abeysekera \& Dawson, 2015).

Determinar quando uma iniciativa é inovadora ou não vai depender do contexto no qual tal iniciativa está sendo desenvolvida. Uma metodologia classificada como não inovadora, num contexto restrito e pontual, pode ser inovadora num contexto mais amplo. Por exemplo, nas áreas de Ciências Humanas e Sociais Aplicadas, é natural o uso da aprendizagem colaborativa ou da sala de aula invertida. Entretanto, no contexto das Ciências Exatas, o emprego dessas metodologias ou de qualquer outra pode ser considerado como inovador, posto que o paradigma das aulas expositivas é predominante nessa área.

Outra crítica comumente encontrada na literatura é quanto à demarcação de uma origem ou filiação para o modelo didático proposto pelas metodologias ativas. Para alguns, essa é uma questão confusa e está longe de ser consensual. Por exemplo, Moreira e Andrade (2018) registram que as metodologias ativas surgiram com uma nova roupagem, uma nova denominação para tendências pedagógicas não tão novas assim e se tornam a sensação do momento, como modelo educacional do século XXI.

Em praticamente todos os trabalhos acerca das metodologias ativas, os autores deixam claro que a sua essência são abordagens teóricas, já consagradas no âmbito da (re) significação da prática docente, voltadas para os processos de ensino e de aprendizagem, pautados nas principais teorias de aprendizagem, a aprendizagem pela experiência, de John Dewey; a aprendizagem significativa de David Ausubel; bem como a perspectiva freiriana da autonomia (Diesel et al., 2017).

As metodologias ativas propõem uma "reinvenção" dessas teorias de modo a aplicá-las no mundo contemporâneo. Por exemplo, Vygotsky, ao sugerir a aprendizagem pela interação social, não imaginava que, nos dias atuais, essa interação poderia se dar por meio remoto com o uso das tecnologias. Raymond Duval, quando desenvolveu a teoria das representações semióticas, não pensou que hoje os alunos poderiam fazer representações de retas, planos e outros objetos matemáticos, num aplicativo instalado em um aparelho que cabe no bolso.

Outro pensamento errôneo acerca das metodologias ativas é presumir que o uso das Tecnologias Digitais da Informação e Comunicação seja imprescindível para que uma metodologia seja caracterizada como ativa. Um professor que utiliza o material dourado, criado por Maria Montessori (1870-1952), como recurso para o ensino e a aprendizagem do sistema 
de numeração decimal-posicional e dos métodos, para efetuar as operações fundamentais, claramente está aplicando uma metodologia ativa.

A discussão acerca da origem dessas metodologias, que contestam a relevância dessas práticas, não contribui para a reflexão crítica e contextualizada quanto à Educação enquanto ciência. Críticas em relação às metodologias ativas desconsideram o fato de que todas as atividades humanas sofreram mudanças drásticas, em sua metodologia, enquanto a educação continuou estagnada em padrões na maneira como nossos estudantes devem aprender.

É importante salientar que a aplicação de uma metodologia ativa pelo professor necessita de um rigoroso planejamento e preparo, pois, ao contrário do que muitos pensam, essas metodologias têm uma complexidade muito maior que as aulas expositivas. Consideramos que, na atualidade, a teoria construída ou as discussões que desconsideram a possibilidade de ressignificação da prática pedagógica, do fazer docente, nega uma característica latente da humanidade: evoluir.

Na próxima seção apresentamos três questões, que a nosso ver, são fundamentais para que essas metodologias não sejam passageiras.

\section{Metodologias Ativas: Modismo? Talvez!}

Por que abordagens teóricas já consagradas, como a aprendizagem pela interação social, de Lev Vygotsky, a aprendizagem pela experiência, de John Dewey, a aprendizagem significativa de David Ausubel, bem como a perspectiva freiriana da autonomia, até hoje não provocaram mudanças significativas na prática do professor na sala de aula? Por que, mesmo diante de tantos avanços tecnológicos e científicos, o modelo de aula continua predominantemente oral e escrito, assim como os recursos utilizados? Essas são perguntas difíceis de derem respondidas. O fato é que, ainda hoje, a cultura das aulas expositivas predomina na maioria das nossas salas de aula e é incontestável que esse modelo não atende às exigências do mundo contemporâneo. Diante desse contexto, Diesel et al. (2017) atentam para o fato que:

"As transformações sociais, econômicas, políticas, culturais e tecnológicas das últimas décadas têm impactado de forma significativa a vida das pessoas, as relações estabelecidas entre elas, o mundo do trabalho e, por conseguinte, a escola”. (p.269)

$\mathrm{O}$ advento da tecnologia e sua popularização trouxeram à tona essas abordagens teóricas já consagradas e permitiu criar estratégias de ensino que propiciam romper (ou ao menos modificar) o modelo tradicional. Contudo a maneira como as denominamos não tem relevância, mas, sim, a eficácia já demonstrada em diversos trabalhos. O grande desafio é: como fazer para que essas metodologias não sejam passageiras? A nosso ver, três questões são fundamentais: compartilhamento de experiências, formação inicial e continuada do professor e desenvolvimento de atividades sustentadas teoricamente.

É fundamental a valorização e divulgação das boas práticas desenvolvidas por professores que estão transformando as salas de aula com o uso dessas metodologias. É possível encontrar, em periódicos nacionais e internacionais, relatos de experiências com metodologias ativas no mundo inteiro, em todos os níveis de ensino, com diversos componentes curriculares e é importante levarmos esses resultados aos professores, tanto do ensino básico quanto superior.

O compartilhamento de práticas educacionais inovadoras e a criação de uma rede de aprendizado, conectando professores de todo o país, ajudariam a inspirar outros educadores e gestores a pensarem, em metodologias inovadoras em sala de aula, além contribuir para que mais escolas conheçam o que tem sido feito na área.

Um cuidado que devemos ter é o de compartilhar práticas que façam uso de todos os tipos de recursos considerando a diversidade de realidades. Não adianta apresentarmos apenas experiências com metodologias ativas que fazem uso de tecnologia, para professores que trabalham na periferia de uma cidade, numa escola sem laboratórios de informática e com alunos que não têm condições de obter tais recursos ou, então, experiências em salas de aulas com 15 alunos, em ambientes 
bem climatizados, sabendo que essa não é a realidade da imensa maioria de nossas escolas.

Regiões mais pobres e afastadas, praticamente esquecidas pelo poder público, são as que mais sofrem com a falta de acesso que vai da tecnologia à alimentação básica. $\mathrm{O}$ abandono do ensino público no Brasil faz com que existam escolas onde falta tudo, educandários que nem de longe lembram uma escola. Por exemplo, segundo Gomes (2018), os cenários vividos no interior do Estado do Amazonas (localizado na região Norte do Brasil) são: salas de aula precárias e abafadas, sem nenhuma climatização, serviço irregular de abastecimento de água e energia nas escolas, merenda escolar escassa ou inexistente e até carência de professores e gestores.

Qualquer metodologia de ensino deve respeitar a cultura de quem aprende. Segundo D'Ambrosio (2015), o cotidiano está impregnado dos saberes e fazeres próprios da cultura e [...] a todo instante, os indivíduos estão comparando, classificando, quantificando, medindo, explicando, generalizando, inferindo e, de algum modo, avaliando, usando os instrumentos materiais e intelectuais que são próprios à sua cultura (D’ambrosio, 2015, p.22).

Nesse contexto, vale salientar que a troca de experiências entre colegas professores do mesmo contexto educacional são fontes riquíssimas de produção do conhecimento e ressignificação da própria prática. Levam professores a olharem para suas práticas, experimentarem mudança e, também, instigando-os a contribuírem com seus relatos de experiência.

Para Masetto (2013, p. 22), "ensinar é um processo social (inserido em cada cultura, com suas normas, tradições e leis), mas é também um processo profundamente pessoal: cada um de nós tem um estilo e um caminho próprio". Portanto fazer e divulgar pesquisas acerca do uso de metodologias ativas, em todos os níveis de ensino, em todos os tipos de espaços e com os mais variados recursos, são uma necessidade prioritária para alavancar o uso dessas metodologias e torná-las amplamente conhecidas no universo educacional.

Em relação à formação inicial e continuada do professor, as transformações sociais, econômicas, políticas, culturais e tecnológicas das últimas décadas exigem do docente uma nova postura e o estabelecimento de uma nova relação entre ele, o aluno e o conhecimento, uma vez que lhe cabe, primordialmente, o planejamento e a condução do processo de ensinoaprendizagem. Diesel et al. (2017) observam que as contínuas e rápidas mudanças da sociedade contemporânea trazem em seu bojo a exigência de um novo perfil docente. Segundo os autores:

É urgente a necessidade de repensar a formação de professores, tendo como ponto de partida a diversidade dos saberes essenciais à sua prática, transpondo, assim, a racionalidade técnica de um fazer instrumental para uma perspectiva que busque ressignificá-la, valorizando os saberes já construídos, com base numa postura reflexiva, investigativa e crítica (Diesel, et al. 2017, p.269).

No que tange aos cursos destinados à formação inicial de professores para a educação básica, suas Diretrizes Curriculares Nacionais (Ministério da Educação Conselho Nacional de Educação Conselho Pleno, n.d.) já determinam que esses cursos devam ter, como um dos seus fundamentos pedagógicos, o compromisso com as metodologias inovadoras. Por outro lado, quando se tece o panorama sobre a formação dos professores, para a educação básica, verifica-se que o cenário geral não é muito animador (Gatti, 2014). Essa mesma autora assevera que há um acúmulo de impasses e problemas historicamente construídos e acumulados, na formação de professores, em nível superior no Brasil, que precisa ser enfrentado. Para essa pesquisadora:

No foco das licenciaturas, esse enfrentamento não poderá ser feito apenas em nível de decretos e normas, o que também é importante, mas é processo que deve ser feito também no cotidiano da vida universitária. Para isso, é necessário poder superar conceitos arraigados e hábitos perpetuados secularmente e ter condições de inovar. Aqui, a criatividade das instituições, dos gestores e professores do ensino superior está sendo desafiada. O desafio não é pequeno quando se tem tanto uma cultura acadêmica acomodada e num jogo de pequenos poderes, como interesses de mercado de grandes corporações (Gatti, 2014, p.36). 
Ao mesmo tempo em que o professor é fundamental, para que as metodologias ativas provoquem modificações significativas em nossa Educação, sua formação, seja inicial ou continuada, tem sido um obstáculo para que isso ocorra. Deborah Ball, da Universidade de Michigan, tem se destacado internacionalmente como uma das principais pesquisadoras em Educação Matemática, preocupada com a formação matemática e didático-pedagógica do professor dessa disciplina. Seus estudos e pesquisas têm apontado o distanciamento entre a prática e a formação necessária ao professor de Matemática. A pesquisadora apresenta três grandes problemas, a serem enfrentados, na formação docente:

O primeiro consiste em identificar o conhecimento de conteúdo que importa para o ensino, o segundo consiste em considerar como tal conhecimento tem que ser estudado e compreendido para ser ensinado e o terceiro consiste em criar oportunidades de aprendizagem do conteúdo de forma a capacitar os futuros professores não somente a ter domínio do conhecimento desses conteúdos, mas, também, saber utilizá-los em contextos variados de prática (Ball, 2000).

Os componentes curriculares dos cursos de formação de professores de Matemática, por exemplo, da maneira como têm sido tratados, na maioria das universidades, com excesso de formalidade, supervalorização do saber acadêmico na sua forma abstrata e o professor como um transmissor de informações, não está direcionada à formação do professor da escola básica, tampouco contribui para formar um professor que vá criar ambientes ou situações didáticas propícias a inovações.

Não podemos esperar que os futuros professores trabalhem com metodologias ativas, se os cursos de formação têm priorizado uma abordagem axiomática, numa linguagem predominantemente simbólico-formal, com ênfase nas demonstrações. Isso certamente cria obstáculos para que as metodologias ativas possam ser apreendidas e aplicadas nas escolas da Educação Básica.

Mudar esse quadro é uma tarefa extremamente complexa. Gatti nos lembra que o histórico legal e institucional dos cursos formadores de professores, por mais de um século, permite-nos avaliar a força de uma tradição e de uma visão sobre um modelo formativo de professores que se petrificou, no início do século XX, com inspiração na concepção de ciências do século XIX e que mostra dificuldades de inovar-se. Segundo a autora:

O esquema de formação híbrido que se consolidou historicamente no país, desde as origens das licenciaturas no início do século passado, postas como adendo dos bacharelados, mostra-se quase impermeável à construção de concepções específicas para a formação de professores tendo a educação e seus aspectos fundamentais como eixo curricular básico. A questão importante, no entanto, é que se oferece nesses cursos apenas um verniz superficial de formação pedagógica e de seus fundamentos que não pode ser considerado como realmente uma formação de profissionais para atuar em escolas na contemporaneidade (Gatti, 2014, p.39).

Se não provocarmos uma ruptura na forma como estamos formando os futuros professores, pouco vai adiantar termos diversas metodologias inovadoras, as quais, para chegar às salas de aula, dependem dos professores. Evidentemente, em uma instituição na qual o uso de metodologias ativas é uma exigência institucional, o professor não terá opção, a não ser fazer usálas. Entretanto têm ocorrido, nessas instituições, cursos de capacitação, muitas vezes, ineficientes para esses docentes.

A questão é que, se o professor fosse preparado, para implementar tais metodologias, os professores da rede pública, por mais dificuldades que tenham, na maioria das vezes, em suas condições de trabalho, teriam em seu repertório um conjunto de estratégias de ensino que poderia ser empregado, de acordo com o contexto por ele vivenciado, mesmo diante de recursos minimamente disponíveis.

É importante não apenas os futuros professores conhecerem as diversas metodologias ativas e aprenderem a utilizálas, mas também que as vivenciem em todos os componentes curriculares de seu curso. Caso contrário, criamos um conflito na percepção do licenciando acerca de como ensinar, pois, ao mesmo tempo em que, nas disciplinas pedagógicas, ele estuda metodologias inovadoras, nas demais, é submetido à metodologia tradicional, na qual ele tem um papel passivo, de escutar, ler, 
decorar e ser repetidor fiel dos ensinamentos do professor.

Não podemos esperar que esse licenciando se torne um professor criativo, crítico, pesquisador e atuante, para produzir conhecimento, contando apenas com a mera sorte e possibilidade dele conseguir articular o conhecimento construído, nas disciplinas pedagógicas, para estabelecer uma reflexão crítica sobre práticas transgressoras.

Se essa situação não mudar, as metodologias ativas tenderão a ter o mesmo destino de outras tendências. Por exemplo, muito se falou em modelagem no ensino da matemática e interdisciplinaridade/transversalidade. Se visitarmos as salas de aula nas escolas públicas na busca de encontrar professores de Matemática que apliquem essas tendências em suas aulas, provavelmente, teremos pouco êxito.

Mas que esperar de um professor que foi formado em um curso no qual se fala muito sobre teoremas do Cálculo, por exemplo, mas fala-se pouco, ou nada, sobre como conectar as ideias fundamentais do Cálculo ao ensino de números reais e de funções na escola, ou sobre como são fundamentais na modelagem e na resolução de problemas?

Devemos ser realistas e aceitar o fato de que ser um exímio matemático não é condição suficiente a fim de formar um professor de Matemática para a Educação Básica e sua diversidade de contexto. Observamos que ainda não existe, no Brasil, um curso específico de formação de docente do Ensino Superior e, por isso, identificamos tantas dificuldades em processos de ensino-aprendizagem, pois, em geral, não recebeu nenhuma formação para isso.

Sendo assim, para que possamos realizar as mudanças nos cursos de formação de professores, faz-se necessário que aqueles que atuam nesses cursos busquem sua formação continuada, como ato de compromisso profissional consigo mesmo, bem como estejam motivados a aprender as novas metodologias de ensino-aprendizagem, para que possam colocá-las em prática dentro de suas aulas. O professor deve ser capaz de se tornar um mestre, ou seja, aquele que não impõe seu saber e nem se coloca em uma postura de quem já sabe tudo e não precisa aprender mais nada. Para obtermos novos resultados, precisamos aprender e fazer as coisas de formas diferentes, criando, recriando, adaptando e testando novas metodologias, de modo que os futuros professores sejam capazes de fazer o mesmo.

Uma metodologia em si corresponde aos procedimentos organizados, aos métodos utilizados num determinado contexto. Podemos dizer que são as regras ou normas estabelecidas para o desenvolvimento de certas atividades. Para Ponte (2014), é pela sua atividade e pela sua reflexão sobre essa atividade que o aluno aprende e, portanto é importante que essas atividades estejam fundamentadas em teorias que demonstrem sua eficácia no sentido de promover a aprendizagem.

É essencial ter presente que uma atividade depende de dois elementos igualmente importantes, a(s) tarefa(s) proposta(s) e a situação didática. Segundo Ponte (2014), é fundamental que o ensino que valoriza o papel ativo do aluno na aprendizagem precisa da noção de tarefa, uma vez que ela constitui o elemento organizador da atividade de quem aprende. No entender de Christiansen e Walther (1986), a proposta de tarefas e a condução da sua resolução na sala de aula, constituem a principal forma como se ensina Matemática.

Para Almouloud (2007), situações didáticas são caracterizadas como um processo de aprendizagem, por meio de uma série de situações reprodutíveis que estabelecem os fatores determinantes para a evolução do comportamento dos alunos. Não adianta o professor propor uma situação didática inovadora se as tarefas presentes nessa situação não forem capazes de promover a aprendizagem. Para exemplificar, apresentaremos três cenários: (1) O professor faz uso da metodologia ativa em sala de aula invertida, visando à aprendizagem de soma de números racionais e, para tanto, disponibiliza vídeoaula para o aluno estudar previamente o tópico. Ao chegar à sala de aula, o professor solicita que os alunos realizem tarefas do tipo "Calcule o valor de $2 / 3+4 / 5 "$; (2) Buscando inserir a tecnologia em suas aulas, o professor solicita que os alunos baixem o software Geogebra em seus celulares e executem tarefas do tipo: "Plote o gráfico da função $f$ dada por $f(x)=2 x-1$ ”; (3) $O$ professor, buscando um novo formato para suas aulas, pede aos alunos formarem grupos, para resolverem uma determinada tarefa. 
No primeiro cenário, ocorre o que David Ausubel definiu como aprendizagem mecânica (ou automática). Nesse tipo de aprendizagem, os alunos armazenam, em sua estrutura cognitiva, novas informações de forma arbitrária, com pouca ou nenhuma interação com conceitos já existentes (subsunçores) nessa estrutura. O conceito central da teoria de Ausubel é o de aprendizagem significativa, segundo o qual é um processo em que uma nova informação se relaciona com um aspecto relevante da estrutura de conhecimento do indivíduo. Neste processo, a nova informação interage com uma estrutura de conhecimento específica, a qual Ausubel define como subsunçor, existente na estrutura cognitiva do indivíduo.

A aprendizagem significativa ocorre, quando a nova informação se ancora em subsunçores relevantes, pré-existentes, na estrutura cognitiva de quem aprende e, para tanto, o material a ser aprendido deve ser potencialmente significativo ao aprendiz que deve manifestar uma disposição de relacionar o novo material de maneira substantiva e não arbitrária à sua estrutura cognitiva. Fica evidente que a tarefa proposta nesse primeiro cenário não é capaz de promover uma aprendizagem significativa.

Essa tarefa pode também ser analisada à luz da teoria das representações semióticas de Raymond Duval. O símbolo $2 / 3+4 / 5$, por si só, corresponde à representação da operação adição entre dois elementos de um conjunto numérico abstrato, conjunto dos números racionais. Com certeza, esse tipo de tarefa não tem potencial de despertar o interesse do estudante para a aprendizagem desse objeto matemático.

No segundo cenário, o uso da tecnologia não traz contribuição relevante para a aprendizagem do aluno. Um dos perigos revelados pelo pesquisador inglês David Tall, na utilização de determinados softwares, que realizam manipulações simbólicas, é que, apesar de eles reduzirem o "fardo" das manipulações simbólicas ao sujeito, eles podem substituir um procedimento realizado com lápis e papel por uma sequência de teclas digitadas (Tall, 2001, p. 213).

Para Tall (1986), o computador pode contribuir, por meio de softwares adequados, a fim de desenvolver materiais significativos a um dado domínio de conhecimento, levando em consideração os obstáculos conhecidos e procurando resolver eventuais conflitos cognitivos de forma adequada. Segundo David Tall (2000), determinados ambientes computacionais (como o Geogebra) podem ser utilizados ao desenvolvimento cognitivo dos aprendizes, permitindo-lhes manipular exemplos e (se possível) contraexemplos de um conceito matemático específico ou de um sistema de conceitos relacionados. Para David Tall, os computadores:

[...] podem executar quaisquer algoritmos de forma rápida e eficiente, além de exibir o resultado final com uma gama de diferentes representações. Por exemplo, os resultados podem ser representados visualmente e manipulados fisicamente. Utilizando um mouse é possível ao estudante construir relações corporificadas que fazem parte de uma estrutura conceitual mais rica e ampla (Tall, 2000, p. 10, tradução nossa)

Na citação acima, David Tall chama a atenção para o fato de os computadores, possibilitarem a exibição de diferentes representações de um mesmo objeto matemático. Neste sentido, adentramos na teoria das representações semióticas de Raymond Duval, segundo a qual um objeto matemático só pode ser acessado, por meio de suas representações e que o aprendiz demonstra ter compreendido o conceito de certos objetos de aprendizagem, se desenvolver a habilidade de reconhecer um mesmo objeto, em suas diversas representações e se for capaz de realizar tratamentos e conversões dessas representações. Logo uma atividade mais rica seria solicitar que os alunos utilizassem o Geogebra, para observar o que acontece com o gráfico da função $f$ dada por $f(x)=2 x-a$, quando a varia no conjunto $\{-2,-1,0,1,2\}$.

O último cenário é aparentemente o mais simples. O professor apresenta o conteúdo e, em seguida, solicita que os alunos formem grupos para realizarem alguma atividade. A questão é que não temos garantia alguma de que esse trabalho será produtivo. É frequente, em nossas escolas, encontrar os estudantes sentados em grupo, mas, na realidade, trabalham individualmente para resolverem as tarefas propostas. Não discutem entre si, não partilham ideias nem material, não cooperam. Nessa situação, o conhecimento teórico do trabalho de Stover e Holland (2018) em que elencam os fatores externos e internos 
que têm impactos na resistência dos estudantes ao trabalho em grupo e no de Jhonson et al. (1998) que apresentam cinco princípios fundamentais para uma cooperação verdadeira e, em consequência, um trabalho em grupo produtivo, forneceria ao professor, condições de contorna a problemática do trabalho em grupo em sala de aula.

Foge ao escopo deste trabalho o aprofundamento acerca das teorias apontadas nos três cenários descritos acima. Nosso propósito é chamar a atenção para o fato de que as metodologias ativas constituem uma condição necessária, mas não suficiente, para que a aprendizagem ocorra. Portanto faz-se necessário analisá-las e discuti-las, criticamente no contexto atual, considerando diferentes perspectivas teórica quanto à aprendizagem. Nossa experiência mostra que as três questões aqui levantadas podem se conectar, quando, um professor em formação inicial, conhece metodologias inovadoras e as aprende a usar, fundamentando suas ações em teorias, uma vez que ensinar requer, tanto dispor de conhecimentos e mobilizá-los para a ação, como compreender o processo de construção do conhecimento e, durante seu estágio, compartilha esse conhecimento com o professor da escola.

\section{Conclusão}

Neste artigo levantamos questões que, no nosso ponto de vista, são capazes de promover discussões iniciais promissoras, no meio acadêmico, na direção de fazer com que as metodologias ativas não sejam apenas um modismo. Essas discussões provam, ainda, uma ruptura relevante no processo de ressignificação do processo ensino-aprendizagem.

Argumentamos ser importante divulgar pesquisas sobre o uso dessas metodologias, em todos os níveis de ensino, em todos os tipos de espaços educacionais e com os mais variados recursos. Expressões como "Cultura Maker", "Gameficação" e "Educação 4.0" já fazem parte da realidade dos alunos de escolas privadas enquanto, para professores e alunos de escolas públicas, principalmente das periferias, esses termos nada significam. É fundamental que professores, que atuam nas escolas públicas de periferia, em comunidades indígenas, na educação especial ou na educação de jovens e adultos, tenham a oportunidade de aproveitar as ideias propostas pelas metodologias ativas. Caso contrário, estaremos apenas aumentando o abismo que há entre ensino público e ensino privado.

Além disso, os docentes formadores de professores nas Universidades precisam aprender essas metodologias e fazer com que suas práticas pedagógicas assumam um formato diferente, criar, recriar, adaptar e testar novas metodologias, de modo que os futuros professores sejam capazes de fazer o mesmo quando forem atuar na Educação Básica. É assumir a condição de ser referência no fazer docente.

Existe a necessidade de analisar e discutir criticamente as metodologias ativas, no contexto atual, considerando diferentes perspectivas teóricas acerca da aprendizagem, como, por exemplo, a Teoria dos Campos Conceituais, de Gerárd Vergnaud; a Teoria das Situações Didáticas, de Guy Brosseau; os estudos em Engenharia Didática, de Michele Artigue; a Teoria das Representações Semióticas, de Raymond Duval, entre outras.

Não consideramos que as metodologias ativas estejam prontas, acabadas e suficientes em si e reconhecemos o processo de evolução pedagógica e metodológica interligada com o processo de evolução humana em todos os seus aspectos. Críticas não construtivas sobre as metodologias ativas em nada contribuem para a Educação, ao contrário, suscitam dúvidas e põem em cheque o trabalho de professores que estão dispostos a mudar suas práticas e veem, nessas metodologias, uma oportunidade para inovar. Vale ressaltar que este estudo não tem a pretensão de necessariamente esgotar o assunto com conclusões definitivas, mas sim contribuir com este debate, que consideramos de suma importância para a garantia de um ensino que realmente promova a aprendizagem, o que certamente é crucial para o desenvolvimento do ensino e, consequentemente, para a melhoria da educação de uma forma geral. 


\section{Referências}

Abeysekera, L., \& Dawson, P. (2015). Motivation and cognitive load in the flipped classroom: definition, rationale and a call for research. Higher education research \& development, 34(1), 1-14.

Almouloud, S. Ag. (2007). Fundamentos da Didática da Matemática. Editora UFPR.

Ball, D. L. (2000). Bridging Practices: Intertwining content and pedagogy in teaching and learning to teach. Journal of Teacher Education, 51(3), 241-247.

Barbosa, E. F., \& Moura, D. G. (2013). Metodologias ativas de aprendizagem na Educação Profissional e Tecnológica. Senac, 39(2), $48-67$.

Bastos, C. C. (2006). Metodologias ativas. http://educacaoemedicina.blogspot.com.br/2006/02/metodologias-ativas.html.

Berbel, N. (2011). As metodologias ativas e a promoção da autonomia dos estudantes. Semina: Ciências Sociais e Humanas, Londrina, 32(1), 25-40.

Christensen, C.M., Horn, M.B., \& Staker, H. (2013). Ensino híbrido: uma inovação disruptiva. Uma introdução à teoria dos híbridos.

Christiansen, B., \& Walther, G. (1986). Task and activity. In B. Christiansen, A. G. Howson \& M. Otte (Eds.), Perspectives on mathematics education, Dordrecht: D. Reidel, 243-307.

Creswell, J. W., \& Creswell, J. D. (2021). Projeto de pesquisa-: Métodos qualitativo, quantitativo e misto. Penso Editora.

da Silva, E. M. (2019). Crítica às metodologias ativas na formação profissional em serviço social. Temporalis, 19(38), 147-161 .

D'ambrosio, U. (2015). Etnomatemática-elo entre as tradições e a modernidade. Autêntica.

Deponti, M. A. M., \& Bulegon, A. M. (2018). Uma revisão de literatura sobre o uso da metodologia sala de aula invertida para o ensino de Física.

Diesel, A.; Baldez, A. L. S., \& Martins, S. N. (2017). Os princípios das metodologias ativas de ensino: uma abordagem teórica. Revista Thema, 14(1), 268288.

Ferreira, M., et al. (2018). Metodologias ativas de aprendizagem aplicadas no ensino da engenharia. CIET: EnPED.

Gatti, B. A. (2014). A formação inicial de professores para a educação básica: as licenciaturas. Revista USP, (100), 33-46.

Gomes, J. (2018). Quase 100\% das comunidades ribeirinhas não tem acesso à internet no AM. 20 de dezembro de 2018. https://d.emtempo.com.br/ciencia-etecnologia-inovacao/131461/quase-100-das-comunidades-ribeirinhas-nao-tem-acesso-a-internet-no-am.

Gil, A. C. (2008). Métodos e técnicas de pesquisa social. (6a ed.), Editora Atlas SA.

Marin, M. J. S., Lima, E. F. G., Paviotti, A. B., Matsuyama, D. T., Silva, L. K. D. D., Gonzalez, C., \& Ilias, M. (2010). Aspectos das fortalezas efragilidades no uso das metodologias ativas de aprendizagem. Revista brasileira de educação médica, 34(1), 13-20.

Masetto, M. (2013). Mediação pedagógica e o uso da tecnologia in Moran, José Manuel.; Masetto, Marcos T.; Behrens, Marilda Aparecida. NovasTecnologias e Mediação Pedagógica.

Ministério da Educação conselho Nacional de Educação Conselho Pleno. (n.d.). http://portal.mec.gov.br/docman/dezembro-2019-pdf/135951-rcp002-19/file

Moran, J. (2017). Metodologias ativas e modelos híbridos na educação. S. YAEGASHI e outros (Orgs). Novas Tecnologias Digitais: Reflexões sobre mediação, aprendizagem e desenvolvimento. Curitiba: CRV, 23-35.

Moreira, M. A., \& de Moura Andrade, M. C. (2018). Metodologias ativas no Ensino Superior: possibilidade ou "faz de conta"? Revista Evidência, 14(15).

Mitre, S. M., Siqueira-Batista, R., Girardi-de-Mendonça, J. M., Morais-Pinto, N. M. D., Meirelles, C. D. A. B., Pinto-Porto, C., \& Hoffmann, L. M. A. (2008). Metodologias ativas de ensino-aprendizagem na formação profissional em saúde: debates atuais. Ciência \& saúde coletiva, 13, $2133-2144$.

Johnson, D., Johnson, R., \& Smith, K. (1998). A aprendizagem cooperativa retorna às faculdades. Change, 3(4), 91-102.

Pacheco, J. (2014). Sala de aula invertida: por que não reagem os pedagogos brasileiros ao neocolonialismo pedagógico. Revista Educação.

Pereira, R. (2012). Método Ativo: Técnicas de Problematização da Realidade aplicada à Educação Básica e ao Ensino Superior. Anais do VI Colóquio Internacional "Educação e Contemporaneidade", São Cristóvão,1-15.

Ponte, J. D. (2014). Tarefas no ensino e na aprendizagem da Matemática. Práticas profissionais dos professores de matemática, 1, $13-31$.

Valente, J. A. (2018). A sala de aula invertida e a possibilidade do ensino personalizado: uma experiência com a graduação em midialogia. Metodologias ativas para uma educação inovadora: uma abordagem teórico-prática. Porto Alegre: Penso, 26-44.

Stover, S., \& Holland, C. (2018). Student Resistance to Collaborative Learning. International Journal for the Scholarship of Teaching and Learning, 12(2), 8.

Tall, D. O. (1986). Building and testing a cognitive approach to the calculus using interactive computer graphics. Ethos.bl.uk. https://ethos.bl.uk/OrderDetails.do?uin=uk.bl.ethos.373184.

Tall, D. O. (2020). Biological brain, mathematical mind \& computational computers (how the computer can support mathematical thinking and learning). In: Asian Technology Conference in Mathematics, 5, 2000, Chiang Mai. Proceedings... Blackwood: ATCM. 
Research, Society and Development, v. 10, n. 14, e330101422046, 2021

(CC BY 4.0) | ISSN 2525-3409 | DOI: http://dx.doi.org/10.33448/rsd-v10i14.22046

Tall, D. (2000). Cognitive development in advanced mathematics using technology. Mathematics Education Research Journal, 12(3), 196-218. https://doi.org/10.1007/bf03217085.

Valério, M., \& Moreira, A. L. O. R. (2018). Sete Críticas à Sala de Aula Invertida. Revista Contexto \& Educação, 33(106), 215. 